\title{
What Drives Ontogenetic Niche Shifts of Fishes in Coral Reef Ecosystems?
}

\author{
I. A. Kimirei ${ }^{1,2}$ I. Nagelkerken,${ }^{1,3 *}$ M. Trommelen, ${ }^{1}$ P. Blankers, ${ }^{1}$ \\ N. van Hoytema, ${ }^{1}$ D. Hoeijmakers, ${ }^{1}$ C. M. Huijbers, ${ }^{1,4}$ Y. D. Mgaya, ${ }^{5}$ \\ and A. L. Rypel ${ }^{6}$
}

\begin{abstract}
${ }^{1}$ Department of Animal Ecology and Ecophysiology, Institute for Water and Wetland Research, Radboud University Nijmegen, P. O. Box 9010, 6500 GL Nijmegen, The Netherlands; ${ }^{2}$ Tanzania Fisheries Research Institute, P. O. Box 90, Kigoma, Tanzania; ${ }^{3}$ Southern Seas Ecology Laboratories, School of Earth and Environmental Sciences, The University of Adelaide, DX 650 418, Adelaide, SA 5005, Australia; ${ }^{4}$ Present address: Australian Rivers Institute-Coast and Estuaries, Griffith University, Gold Coast campus, Nathan, QLD 4222, Australia; ${ }^{5}$ Department of Aquatic Sciences and Fisheries, University of Dar es Salaam, P. O. Box 60091, Dar es Salaam,

Tanzania; ${ }^{6}$ Department of Fish and Wildlife Conservation, Virginia Tech, 100 Cheatham Hall, Blacksburg, Virginia, USA
\end{abstract}

\begin{abstract}
Ontogenetic niche shifts are taxonomically and ecologically widespread across the globe. Consequently, identifying the ecological mechanics that promote these shifts at diverse scales is central to an improved understanding of ecosystems generally. We evaluated multiple potential drivers of ontogenetic niche shifts (predation, growth, maturation, diet shifts, and food availability) for three fish species between connected coral reef and nearshore habitats. In all cases, neither diet compositional change nor sexual maturity functioned as apparent triggers for emigration from juvenile to adult habitats. Rather, the fitness advantages conferred on reef inhabitants (that is, enhanced growth rates) were primarily related to high prey availability on reefs. However, there exists a clear
\end{abstract}

trade-off to this benefit as survival rates for small fishes were significantly reduced on reefs, thereby revealing the potential value of (and rationale behind high juvenile abundances in) nearshore habitat as predation refugia. We ultimately conclude that predation risk functions as the primary early life stage inhibitor of ontogenetic niche shifts towards more profitable adult habitats in these systems. Furthermore, this study provides a case study for how complex, meta-dynamic populations and ecosystems might be better understood through the elucidation of simple ecological trade-offs.

Key words: survival; food abundance; growth; trade-offs; coral reef; mangrove; seagrass.
Received 10 September 2012; accepted 10 January 2013; published online 27 February 2013

Electronic supplementary material: The online version of this article (doi:10.1007/s10021-013-9645-4) contains supplementary material, which is available to authorized users.

Author contributions: IAK, IN, YDM—designed the study, IAK, MT, $\mathrm{PB}, \mathrm{NvH}, \mathrm{DH}, \mathrm{CMH}-$ performed the research, IAK, IN, ALR, $\mathrm{CMH}$ - analyzed the data, and IAK, IN, ALR—wrote the paper.

*Corresponding author; e-mail: ivan.nagelkerken@adelaide.edu.au

\section{INTRODUCTION}

Ontogenetic niche shifts are extremely common features of the life-cycles of diverse organisms (Werner and Gilliam 1984; Fryxell and Sinclair 1988; Post 2003). Understanding the mechanisms that promote these shifts is a highly active area of 
research in ecology as important variables would clearly be implicated in population stability and ecosystem function at multiple scales (Brodersen and others 2008). Various hypotheses have been generated for explaining the ecological basis for niche shifting in animals. These include conditional differences between individuals (Jonsson and Jonsson 1993; Kaitala and others 1993; Brodersen and others 2008), strong inter- and intra-specific competition (Cox 1968; Biebach 1983), genetic differences between migrants and residents (Biebach 1983), or a mixed evolutionary stable strategy resulting from frequency-dependent selection (Kaitala and others 1993). However, current knowledge on the drivers of niche shifts is overwhelmingly dominated by vertebrate species in terrestrial environments (Cox 1968; Lundberg 1987, 1988; Kaitala and others 1993) even though niche shifts in aquatic ecosystems and species are equally common. For example, salmon and other anadromous fish species migrate from oceans to spawn upstream in rivers at specific sizes and ages (Jonsson and Jonsson 1993). Similarly, freshwater fishes perform both large- and small-scale migrations in rivers (for example, from lentic backwater habitats into main channel areas during floods), all of which are known to involve trade-offs between seasonal fluctuations in predation risk and growth potential (Schindler 1999; Brodersen and others 2008; Skov and others 2011; Rypel and others 2012).

As opposed to basic niche shifts, that can vary depending on their function and temporal scale (for example, diel migrations or seasonal spawning migrations), ontogenetic niche shifts have a more permanent and unidirectional character. Yet, both theoretical and empirical studies suggest that the benefits of permanent niche shifts must outweigh the associated risk of movement for them to actually occur (Dahlgren and Eggleston 2000; Grol and others 2011; Rypel and others 2012). In coastal marine environments, daily and seasonal variations in abiotic factors, such as temperature, salinity and turbidity, can apparently trigger migrations (Travers and others 2006). However, key biotic drivers (for example, predation and competition) could be equally important (Jonsson and Jonsson 1993; Edgar and Shaw 1995; Hyndes and others 1997; Verweij and others 2006; Grol and others 2011).

Optimal foraging theory predicts that foraging behaviors are a product of prey profitability and size selection by predators (Werner and Hall 1988). Thus, as the dietary needs of animals expand during ontogeny (Laegdsgaard and Johnson 2001), a need or advantage to shifting habitats often arises. However, niche shifts could just as easily result from the onset of sexual maturity and the biological need to seek reproductive partners or to move to environments that promotes spawning and enhances gamete survival-an iconic example being the longdistance spawning migrations of oceanic salmon to natal riverine spawning zones (Ueda 2011; review by Leggett 1977). Yet, although multiple studies have focused on single drivers of ontogenetic habitat migrations, few studies have endeavored to examine multiple drivers.

In tropical seascapes, ontogenetic niche shifts are especially common. The principle pattern usually involves fishes shifting from vegetated nearshore juvenile habitats (for example, mangroves, algal fields, seagrass beds) to spatially segregated deepwater adult habitats (for example, coral reefs, offshore shelf areas) (Nagelkerken and others 2002; Dorenbosch and others 2005a, b; Adams and others 2006; Nagelkerken 2007; Nakamura and others 2008; Shibuno and others 2008; Kimirei and others 2011). These size-related habitat shifts may be a strategy to minimize mortality and maximize growth (Dahlgren and Eggleston 2000; Grol and others 2011). However, little empirical evidence exists to disentangle the multiple sub-factors that underlie these ecological phenomena. For example, the availability of prey (Galarowicz and others 2006), size-specific changes in diet (McCormick and Makey 1997), predation risk (Grol and others 2011), and growth (McCormick 1998) may all influence ontogenetic niche shifts by marine fishes at some level.

In this study, we examine multiple drivers of ontogenetic niche shifts from juvenile to adult habitats in several species of coral reef fish. We hypothesized that an ontogenetic switch to large prey items becomes a limiting factor at some point during early life growth in juvenile habitats, ultimately reducing growth (and thus also maturation) rates in nearshore habitats, thereby incentivizing a potential habitat switch to reefs. We examined differences in diet, growth, maturity, and survival from predation among habitats through ontogeny, coupled to differences in food abundances. This enabled us to critically evaluate the degree to which these ecological factors differ among habitats and life stages, and why and when ontogenetic niche shifts may occur more generally in tropical coastal environments.

\section{Materials AND Methods}

\section{Study Area}

The study was conducted in a large shoreline-island-reef complex near Kunduchi, Dar es Salaam, Tanzania (Figure 1). Major marine habitats sam- 


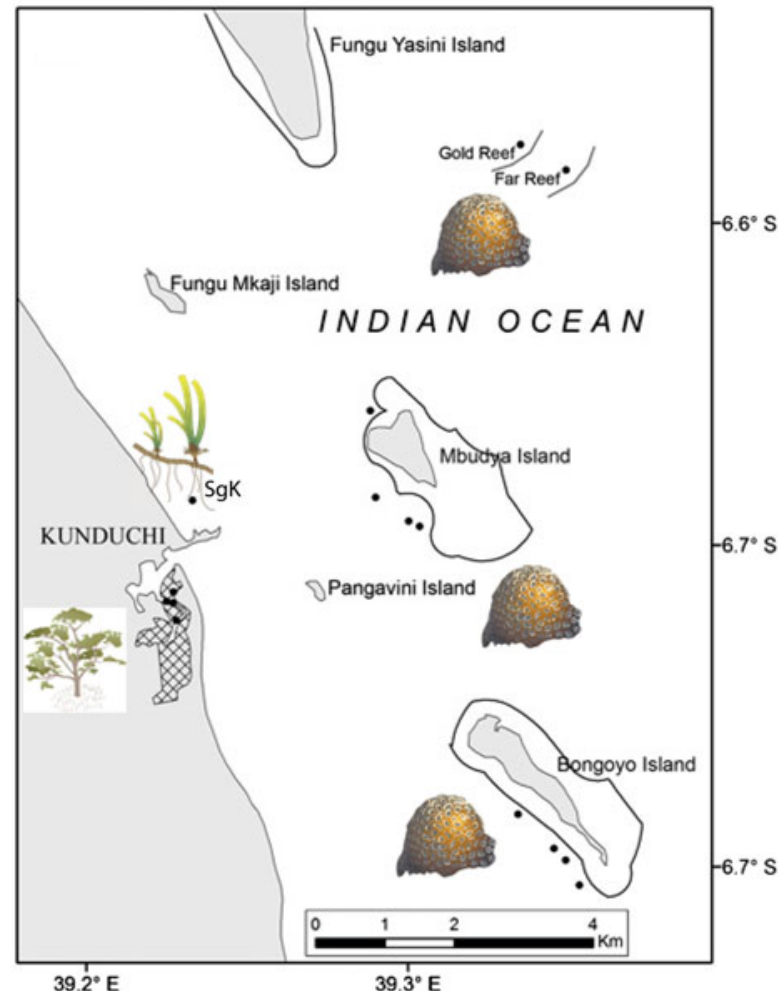

Figure 1. Map of study area. Reef contours (approximately $17 \mathrm{~m}$ depth) are indicated by thick black lines. Hatched area indicates location of the mangrove forest. SgK seagrass Kunduchi. Black dots indicate the study sites; at Mbudya and Bongoyo Islands each dot represents a neighboring reef and seagrass site. Image credits: Christine Thurber, Catherine Collier \& Tracey Saxby, IAN Image Library (ian.umces.edu/imagelibrary).

pled in the study area consisted of mangroves, seagrass beds and coral reefs. The mangrove forest on the mainland is dominated by Sonneratia alba and freshwater input into the system is only substantial during heavy rainfall. The offshore islands (Mbudya and Bongoyo) are fringed by shallow coral reefs followed by seagrass beds at greater depths. Seagrass beds also occur along the coastline of the mainland. 'Far reef' and 'Gold reef' are submerged patch reefs dominated by massive coral colonies and a variety of soft corals.

\section{Fish Sampling}

Individuals of three fish species (Lethrinus harak, Lethrinus lentjan, and Lutjanus fulviflamma) were collected from the three focal habitats and analyzed for stomach content, gonadal maturation, and age estimation by analysis of otolith sagittae (Table 1). All fish collections took place concurrently with underwater visual census surveys to estimate fish abundances in the same habitats on a monthly basis over 2 years (Kimirei and others 2011). Fishes from mangrove habitat were collected with a $1 \times 10 \mathrm{~m}$ seine dragged against the current during outgoing tide. Hook and line angling, and a fyke net were used to supplement fish catch in the mangrove habitat and guard against gear selectivity in fish size. Fishes captured using baited hook and line were not used for stomach content analysis. Fishes from the seagrass beds were purchased from local fishermen that utilized beach seines at low tide. Specimens from coral reef habitats were captured using a spear gun. All fishes were either immediately analyzed or kept in a freezer pending analysis the following day.

For each fish, total length was measured to the nearest $\mathrm{mm}$ (Table 1). For diet analysis, stomach contents were analyzed under a stereomicroscope and all prey items identified to the lowest possible taxonomic level (Supplementary Table 1). Proportions of food items in each stomach were estimated in relative volumetric quantity of the food items, that is, the volume of the contents of the stomach was set at $100 \%$ and the food items found were estimated by eye, as a volumetric percentage of the total stomach volume (Hyslop 1980; Cocheret de la Morinière and others 2003a). Gravimetric methods were not used due to large errors associated with measuring small stomach volumes of juvenile fish which also contain water (blotting may damage the samples), whereas methods that involve frequency estimation would underestimate large food items and overestimate small food categories (Hyslop 1980).

Otolith sagittae were removed from each fish and used to estimate the age of each fish. Each otolith was cross-sectioned using standard methodology (Maceina 1988) and examined under a dissecting microscope utilizing reflected light. Ages were determined blindly (that is, with no knowledge of the sample number or fish size) twice by an experienced reader, and disagreements between reads one and two (4\% of all samples) were settled using another experienced reader.

For maturity analysis, gonads were used to visually determine sex and stage of maturity. Maturity stages were based on a seven point staging key modified from Ntiba and Jaccarini (1990), KaundaArara and Ntiba (1997), and Kulmiye and others (2002). Stages I, II $a$, III, IV, V, VI and II $b$ represented immature, developing, maturing (active), ripe, fully ripe and spawning, just spawned, and recovering, respectively.

\section{Abundance of Prey Items}

Quantification of potential prey abundance across habitats was conducted during July-November 
Table 1. Overview per Habitat and Fish Species of Size Range (Total Length), Number of Full Stomachs Analyzed for Content, Number of Otoliths Analyzed for Age, and Number of Gonads Used for Maturity Analysis, Including Percent Immature (Stages I and II) and Mature (II $b$ and III-VI) Gonads

\begin{tabular}{|c|c|c|c|c|c|c|}
\hline \multirow{2}{*}{$\begin{array}{l}\text { Species } \\
\text { Habitat }\end{array}$} & \multirow[t]{2}{*}{ Size-range $(\mathrm{cm})$} & \multirow[t]{2}{*}{ Stomachs } & \multirow[t]{2}{*}{ Otoliths } & \multicolumn{3}{|c|}{ Gonads } \\
\hline & & & & Total & Immature (\%) & Mature (\%) \\
\hline \multicolumn{7}{|c|}{ Lethrinus harak } \\
\hline Mangrove & $3.2-29.6$ & 5 & 36 & 23 & 100 & 0 \\
\hline Seagrass & $5.1-28.0$ & 31 & 81 & 130 & 82 & 18 \\
\hline Coral reef & $24.6-39.6$ & 20 & 20 & 54 & 0 & 100 \\
\hline \multicolumn{7}{|c|}{ Lethrinus lentjan } \\
\hline Mangrove & $3.7-9.0$ & 2 & 0 & 4 & 100 & 0 \\
\hline Seagrass & $5.6-21.7$ & 68 & 125 & 287 & 95 & 5 \\
\hline Coral reef & $10.4-38.4$ & 70 & 84 & 90 & 11 & 89 \\
\hline \multicolumn{7}{|c|}{ Lutjanus fulviflamma } \\
\hline Mangrove & $1.7-16.1$ & 257 & 86 & 488 & 100 & 0 \\
\hline Seagrass & $2.6-24.0$ & 160 & 159 & 492 & 74 & 26 \\
\hline Coral reef & $16.2-20.3$ & 20 & 43 & 26 & 0 & 100 \\
\hline Total & & 633 & 634 & 1594 & & \\
\hline
\end{tabular}

2008. A $50 \times 50 \mathrm{~cm}$ quadrat was randomly placed in each of the three habitats and all flora and loose substrate within the quadrat collected by hand and placed into a bag. Only epifauna were collected because the studied fish species feed on slowmoving prey on the substratum or those associated with the vegetation (Carpenter 1996). For seagrass beds, all seagrass shoots were carefully cut and collected into a hand-closed plastic bag to minimize escape of prey. For mangroves, the roots were cut off and all loose pieces collected in a plastic bag. Similarly, for coral reefs all detached corals were collected. A total of 6, 13, and 12 quadrats were sampled in the mangrove, seagrass and reef habitats, respectively. Water was drained from the samples which were subsequently stored at $-20^{\circ} \mathrm{C}$ pending analysis. All collected substrates and vegetation, along with the interiors of dead mangrove roots were visually inspected for potential food items larger than $2 \mathrm{~mm}$.

\section{Survival from Predation}

Differences in relative survival rates among habitats were estimated using tethering experiments for two of the focal species (L. fulviflamma and L. harak). Insufficient specimens could be obtained for the third species. Fish of three different size classes for each species $(1-4,7-10$, and $13-16 \mathrm{~cm})$ were subsequently tethered during daytime in seagrass beds, mangroves, and on the coral reef. Individual fish were attached by a barbed hook through the lower jaw to a thin length $(50-80 \mathrm{~cm})$ of light monofilament line. The barb effectively avoided escape of the fish from the tether. The line length was selected such that the fish were able to hide within the bottom vegetation. The line was attached to an iron pole $(\sim 40 \mathrm{~cm})$ that was anchored into the substratum. Each tethering trial lasted $90 \mathrm{~min}$, after which the total number of surviving fish was determined. Tethering lines that were devoid of the fish as well as the hook were a clear case of predation. In some cases, the hook was still attached to the line but the fish was gone. As the number of cases in which this occurred was approximately three times higher for the smallest size class of fish than for the largest size class we are confident that this resulted from predation. We used the same hook size and line thickness for all fish, so in case fish escaped this would be most evident for the larger, stronger fish. However, we found the exact opposite pattern. Furthermore, we looked at the fish predation patterns based only on broken tethering lines devoid of fish and hook, as well as based on all cases of missing fish (that is, broken lines plus intact lines with hook but devoid of fish). The same pattern was evident for both approaches so we are confident that the technique was not biased by fish escapes. Furthermore, the hooks had a protruding barb making it very difficult for the hooks to be detached from the bony fish mouths. For both fish species, trials were conducted at two sites per habitat, except for L. harak in 
mangrove habitat which was only conducted at one site. During each trial, 6-14 fish (average: 10 fish per trial) were tethered simultaneously. Different size classes and species were never tethered in the same trial, and the sequence of tethering was done randomly across different sites, species and size classes.

\section{Data and Statistical Analysis}

Food items identified from stomachs were grouped into two main categories per fish species and habitat. The first category comprised all large prey items and included fish, large crustaceans (crabs, shrimps), worms (Polychaeta, Oligochaeta, Nematoda), mollusks (Gastropoda, Bivalvia and Cephalopoda), and Echinoidea. The second category consisted of all small prey items and included all small crustaceans (Copepoda, Isopoda, Amphipoda, Tanaidacea, Mysidacea, Cumacea, and Ostracoda). The dietary proportions of these two main prey categories were then computed per fish size class ( $1 \mathrm{~cm}$ classes) and habitat for each species separately, and plotted as a function of fish size. A power function (allometric) of the form $y=a * x^{b}$ (where $a$ and $b$ are constants) was fitted to these data.

Food abundance data were statistically compared only for those items that were most common in the stomachs of the three fish species, using an unbalanced nested ANOVA (as habitats had different numbers of sites sampled) with sites nested under habitats. Comparison of means was done by a Gabriel post-hoc test, or a Games-Howell posthoc test as a non-parametric alternative when variances were still heterogeneous after data transformation. The data were tested for homogeneity of variance using a Levene's test, and log- or square root-transformed prior to analysis. SPSS 16 was used for all analyses, unless otherwise stated.

In addition, the mean abundance of large prey items available per individual fish was estimated for each habitat. Only commonly consumed large prey items were included. A food item was considered common if at least $25 \%$ of all stomachs analyzed contained at least $10 \%$ volume of that particular food item (see Supplementary Table 1). These were large crustaceans for all fish species in all habitats, in addition to Mollusca and Echinoidea for L. harak on the reef, Echinoidea for L. lentjan on the reef, and worms for L. lentjan on the seagrass beds. At the transect/quadrat level, total density of large food items for the respective fish species in the respective habitats (mangrove, seagrass, and coral reef) was then divided by the total density of fish larger than $5 \mathrm{~cm}$ total length in the respective habitat per species. A cut-off size of $5 \mathrm{~cm}$ was used as at this size fishes had largely shifted in diet to larger prey items (see "Results"). Fish density data used to calculate the amount of prey items available per individual fish were obtained from a different study (Kimirei and others 2011), using underwater visual census surveys in belt transects at the same sites and during the same period as this study. A one-way ANOVA followed by a Gabriel post-hoc test was used to determine whether food density per fish differed among habitats.

Growth analysis was based on fish age obtained from the otolith analyses. For each species, fish growth was modeled using the Von Bertalanffy Growth Function, $L_{t}=L_{\infty}\left[1-\mathrm{e}^{-\mathrm{k}(t-t)}\right]$, where $L_{t}=$ length at time $t, L_{\infty}=$ the theoretical maximum length, $k=$ a growth coefficient (the rate at which length approaches $L_{\infty}$ ), $t=$ fish age in years, and $t_{0}=$ theoretical time at age 0 . However, because growth is completed over several habitat types, and is generally non-asymptotic, differences in growth between habitats for each species (for example, seagrass vs. mangrove) were evaluated using analysis of covariance (ANCOVA) combined with Tukey's post-hoc tests. In these models, TL was the dependent variable, $\log _{10}$ (age) was a covariate, and habitat type was a categorical variable (Rypel 2011).

For maturity analysis, proportions of immature (stages I and II $a$ ) and mature (III, IV, V, VI and II $b$ ) individuals were computed per size class $(1 \mathrm{~cm}$ increments) per habitat. The proportion of mature individuals $(\%)$ was plotted as a function of total fish length $(\mathrm{cm})$ and fitted with a sigmoid logistic function of the form: $y=A_{2}+\left(A_{1}-A_{2}\right) /(1+(x)$ $\left.x_{0}\right)^{\mathrm{p}}$ ) (where $A_{1}=\max , A_{2}=\min$, and $p=3$ are constants). Fish density in the adult habitat (that is, shallow and deep coral reefs and deep mud flats pooled) were averaged per centimeter, expressed as a percentage of the total density of all habitats for the respective size class, and also fitted with a sigmoid logistic curve. The size at which fish initiate migration from juvenile to adult habitat was defined as the size (total length) at which $25 \%$ of the total density occurred in the adult habitat.

Survival rate was measured in percentage survival at the end of the tethering experiment. For each of the three fish size classes in each of the three habitats, replicates consisted of the trials done at the various sites and combining the two species to obtain sufficient data for statistical analysis. Three logistic regressions were used to compare differences in survival among habitats for each size class. In each regression, survival was used as a 

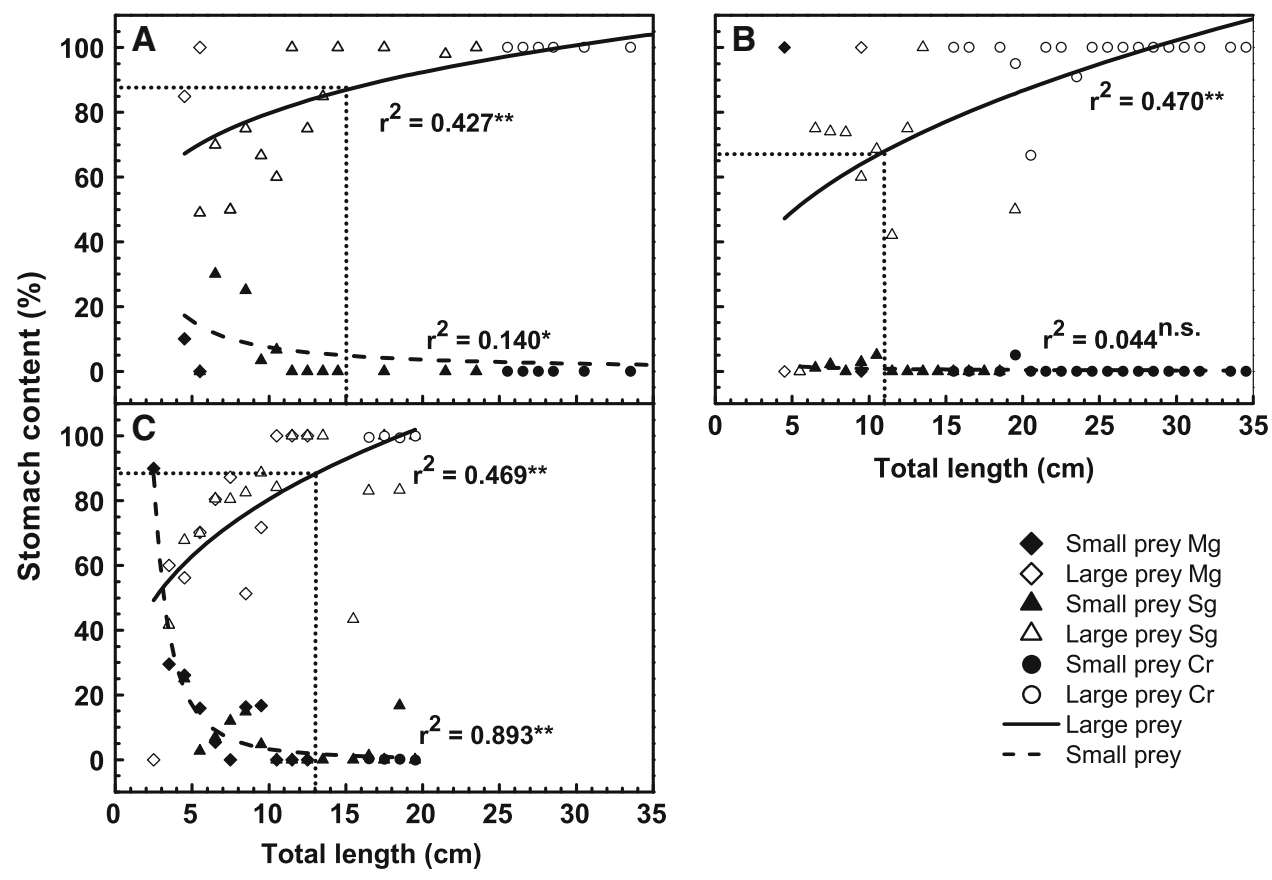

Figure 2. Mean stomach content (volumetric \%) per fish size class ( $1 \mathrm{~cm}$ increments in total length) in different habitats for small and large food items (see "Materials and Methods" for details) for A Lethrinus harak, B Lethrinus lentjan, and C Lutjanus fulviflamma. Continuous and dashed lines are fitted regression lines based on a power function; associated $r^{2}$ values are shown as well. The single outlier in $\mathbf{B}$ for small prey in mangroves was not included in the regression analysis. Fine dotted lines indicate the proportion of large food items in the diet at the onset of habitat migration, as defined by $25 \%$ of the fish density observed in adult habitat; it was determined from Figure 6 (see "Materials and Methods" for clarification). $M g$ mangrove, $S g$ seagrass, $C r$ coral reef, ${ }^{*} P<0.01,{ }^{*} P<0.001$, n.s. not significant $(P>0.05)$.

dependent variable, and habitat type was used as a categorical variable.

\section{RESULTS \\ Ontogenetic Diet Shifts}

The importance of combined large food items increased significantly with fish length for all species (Figure 2). L. harak larger than $13 \mathrm{~cm}$ fed entirely on large prey items $(100 \%)$ in the seagrass and on the reef; prey items consisted mainly of large crustaceans and fish in the seagrass beds, and on the reef also of worms, mollusks and echinoderms (Supplementary Table 1). For L. lentjan, the large prey items consumed were composed mainly of large crustaceans and fish, and in the seagrass beds also of worms. L. lentjan consumed large proportions of echinoderms $(35-80 \%)$ on the coral reef. L. fulviflamma larger than $9 \mathrm{~cm}$ fed for greater than $80 \%$, on average, on large prey items in the seagrass and coral reef; these consisted mainly of fish, crabs, and shrimps with varying proportions per size class and habitat.

Two species (L. harak and L. fulviflamma) showed a significant decrease in the proportion of small food items consumed with body size, whereas L. lentjan showed minor consumption of small food items across all size classes (Figure 2). The ontogenetic diet shift from small to large prey items was evident at a very early life stage $(\sim 5 \mathrm{~cm})$, well before the ontogenetic movement to the coral reef seemed to occur. The size at which approximately $25 \%$ of the total fish density was observed in the adult habitat (indicating an approximate start of ontogenetic niche shifts), coincided strongly with feeding on large food items $(65-90 \%$ of the stomach content as predicted by the allometric regression lines, Figure 2).

\section{Abundance of Prey Items}

The mean density of large prey species differed significantly among habitats for decapods and echinoids (nested ANOVA, $F_{2,14.4}=5.225, \quad P=$ 0.020 and $F_{2,21.8}=4.322, P=0.026$, respectively). Decapods and echinoids were significantly more abundant on coral reefs than in mangroves and seagrass beds (Figure 3, Gabriel post-hoc tests, $P<0.015$ and $P<0.050$, respectively). Molluscs showed no overall significant habitat differences (nested ANOVA, $\left.F_{2,12.9}=1.834, P=0.199\right)$, but 
had a significant nested term $\left(F_{11,17}=2.768\right.$, $P=0.029)$ indicating that at some collection sites mangroves had significantly lower molluscs abundances than seagrass beds (Figure 3, Gabriel post-hoc test, $P=0.050$ ). Small prey items like amphipods were significantly more abundant on

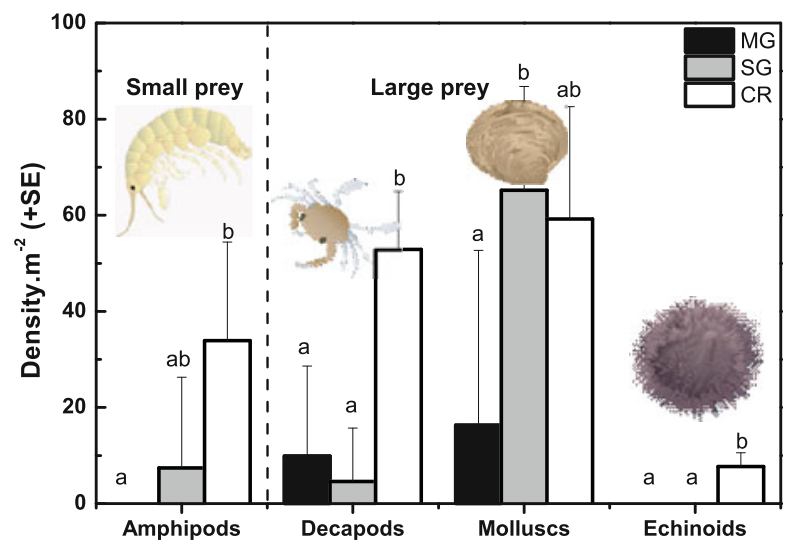

Figure 3. Density $\left(\mathrm{m}^{-2}\right)$ of predominantly consumed small and large food items in different habitats (epifauna). The different food categories are similar to those used in Figure 2 (see "Materials and Methods" for details). Within each prey group, significant differences among habitats $(P<0.05$, based on Gabriel or Games-Howell post-hoc tests) are indicated by letters ( $a$ and $b$ ) above the bars; if bars have a letter in common they do not differ, if bars do not have a letter in common they differ. Decapods consist of crabs and shrimp. $\mathrm{Mg}$ mangrove, $\mathrm{Sg}$ seagrass, $\mathrm{Cr}$ coral reef. Image credit: Tracey Saxby, IAN Image Library (ian.umces.edu/imagelibrary). coral reefs than in the mangroves (Games-Howell post-hoc test, $P=0.048$; Figure 3 ).

The abundance of large prey items available per individual fish in the different habitats was highest in the intertidal mangroves and on the coral reef for L. harak and L. lentjan (Figure 4). Conversely, for L. fulviflamma, the largest quantities of potential prey per individual were available in the seagrass beds, followed by the coral reef.

\section{Growth}

The Von Bertalanffy growth coefficients for L. harak, L. lentjan, and L. fulviflamma were $L_{\alpha}=49.2$, 46.1, and 21.1, $K=0.07,0.06$, and 0.32, $T_{\mathrm{o}}=$ $-2.00,-2.76$, and -0.70 , respectively. Growth was significantly higher for fish from the coral reef compared to those from the seagrass beds or mangroves, for each of the three fish species (Figure 5; Table 2). For L. fulviflamma, size at age was also significantly higher for seagrass fish than for mangrove fish. Furthermore, although size at age was significantly higher on the reef for this species, the slope of the reef length-at- $\log _{10}$ (age) regression was reduced for this species indicating a lower rate of growth for large fish.

\section{Maturation}

Maturation was a function of size, but not of habitat type. Logistic curves best explained the variability in percent maturation as a function of fish size $\left(r^{2}>0.97\right)$ and all fitted curves were
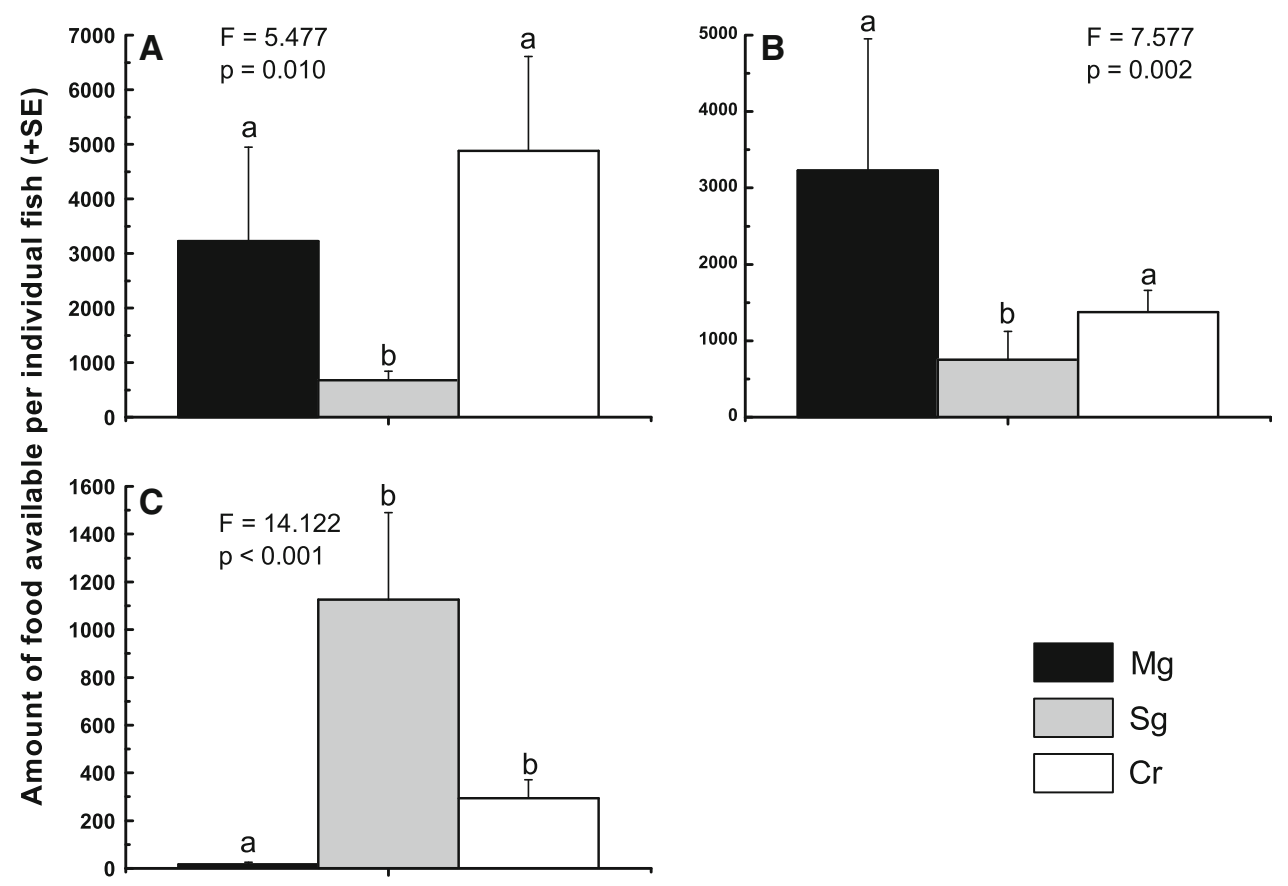

Figure 4. Number of large food items available per individual fish in different habitats for $\mathbf{A}$ Lethrinus harak, B Lethrinus lentjan, and $\mathbf{C}$ Lutjanus fulviflamma. ANOVA $F$ - and $P$ values are provided per species. For each fish species, significant differences among habitats $(P<0.05$, based on a Gabriel post-hoc test) are indicated by letters ( $a$ and $b$ ) above the bars; if bars have a letter in common they do not differ, if bars do not have a letter in common they differ. $\mathrm{Mg}$ mangrove, $\mathrm{Sg}$ seagrass, $\mathrm{Cr}$ coral reef. 

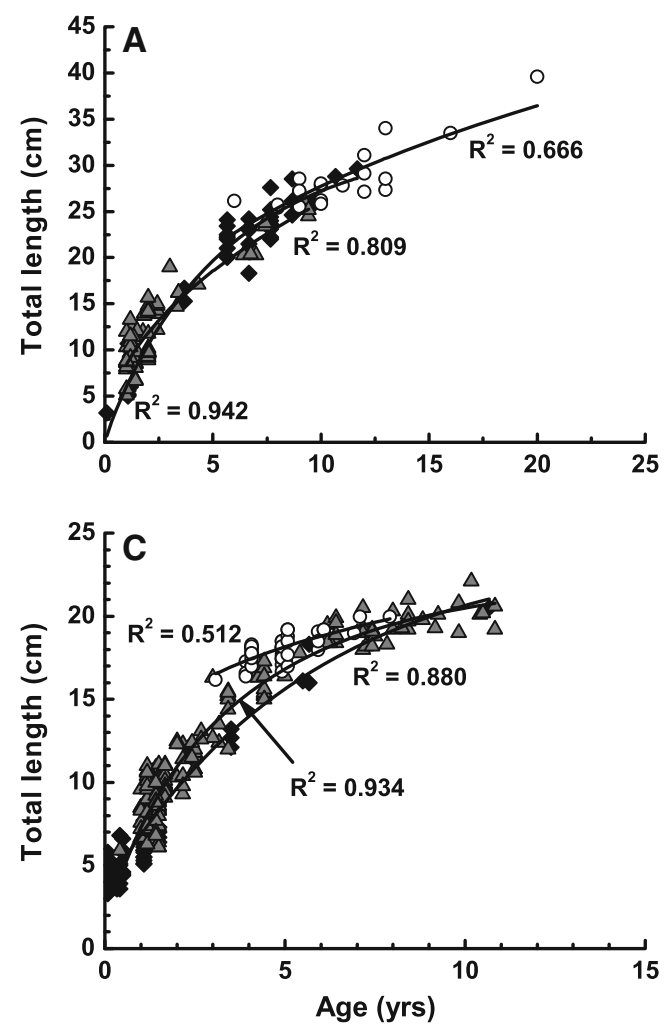

B

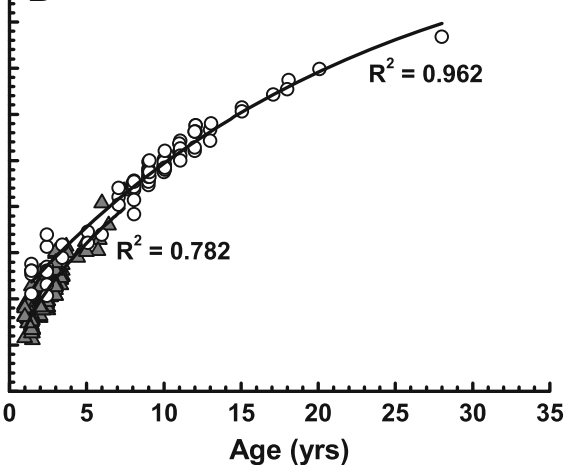

Figure 5. Length-at-age for A Lethrinus harak, B Lethrinus lentjan, and $\mathbf{C}$ Lutjanus fulviflamma in various habitats fitted to a logarithmic growth function with associated $r^{2}$ values. $M g$ mangrove, $\mathrm{Sg}$ seagrass, $\mathrm{Cr}$ coral reef.

Table 2. Results of ANCOVA Evaluating Growth Differences for Three Species Among Habitat Types

\begin{tabular}{llllllll}
\hline Species & Model & & & Log age & Cr vs. Sg & Cr vs. Mg & Mg vs. Sg \\
\cline { 2 - 4 } & \multicolumn{1}{c}{$F$} & $P$ & $R^{2}$ & & & & \\
\hline L. harak & 657 & $<0.001$ & 0.94 & $<0.001$ & 0.030 & 0.020 & 0.660 \\
L. lentjan & 2267 & $<0.001$ & 0.96 & $<0.001$ & $<0.001$ & N/A & N/A \\
L. fulviflamma & 1596 & $<0.001$ & 0.94 & $<0.001$ & $<0.001$ & $<0.001$ & 0.001
\end{tabular}

Cr coral reef, Sg seagrass, $M g$ mangrove.

significantly different from a value of zero (Figure 6). However, the maturation curves did not vary significantly among habitats for any of the species (ANCOVA, $F=0.938,1.500$ and 0.864 for L. harak, L. lentjan, and L. fulviflamma, respectively; $P>$ 0.236). The size at first maturity $\left(L_{50}\right)$, defined as the size at which $50 \%$ of all individuals were mature, varied by less than $1 \mathrm{~cm}$ among habitats for L. lentjan ( 14.0 and $14.7 \mathrm{~cm}$ in seagrass beds and on coral reefs, respectively) and for L. fulviflamma (15.8 and $16.0 \mathrm{~cm}$ in the mangroves and seagrass beds, respectively). In all cases, $L_{50}$ occurred at a larger body size than that at which individuals appeared to move to the adult habitat (Figure 6). No significant differences were found in maturity at size between female and male fish within habitats for any of the species (ANCOVA, $F=0.001,0.183$, and 4.039 for $L$. harak, L. lentjan, and L. fulviflamma, respectively;
$P>0.079$ for all species and habitats), and the $L_{50}$ values were similar for male versus female fish (differences between male/female $L_{50}$ across habitats and species were $<1 \mathrm{~cm}$ ).

\section{Survival}

Survival rate of tethered fish in all habitats increased with fish size (Figure 7), but with significantly higher survival of the smaller $(1-4 \mathrm{~cm}$ TL) and medium size $(7-10 \mathrm{~cm})$ fishes in the mangroves $\left(\chi^{2}=17.753, P<0.001\right.$ and $\chi^{2}=7.939, P=0.005$ for the small and medium sizes, respectively) and seagrass beds $\left(\chi^{2}=27.315, P<0.001\right.$ and $\chi^{2}=$ 7.768, $P=0.005$ for small and medium sizes, respectively) than on the coral reef. While survival rate was just below $40 \%$ for the $1-4 \mathrm{~cm}$ size class in the mangroves and seagrass beds, it was greater 

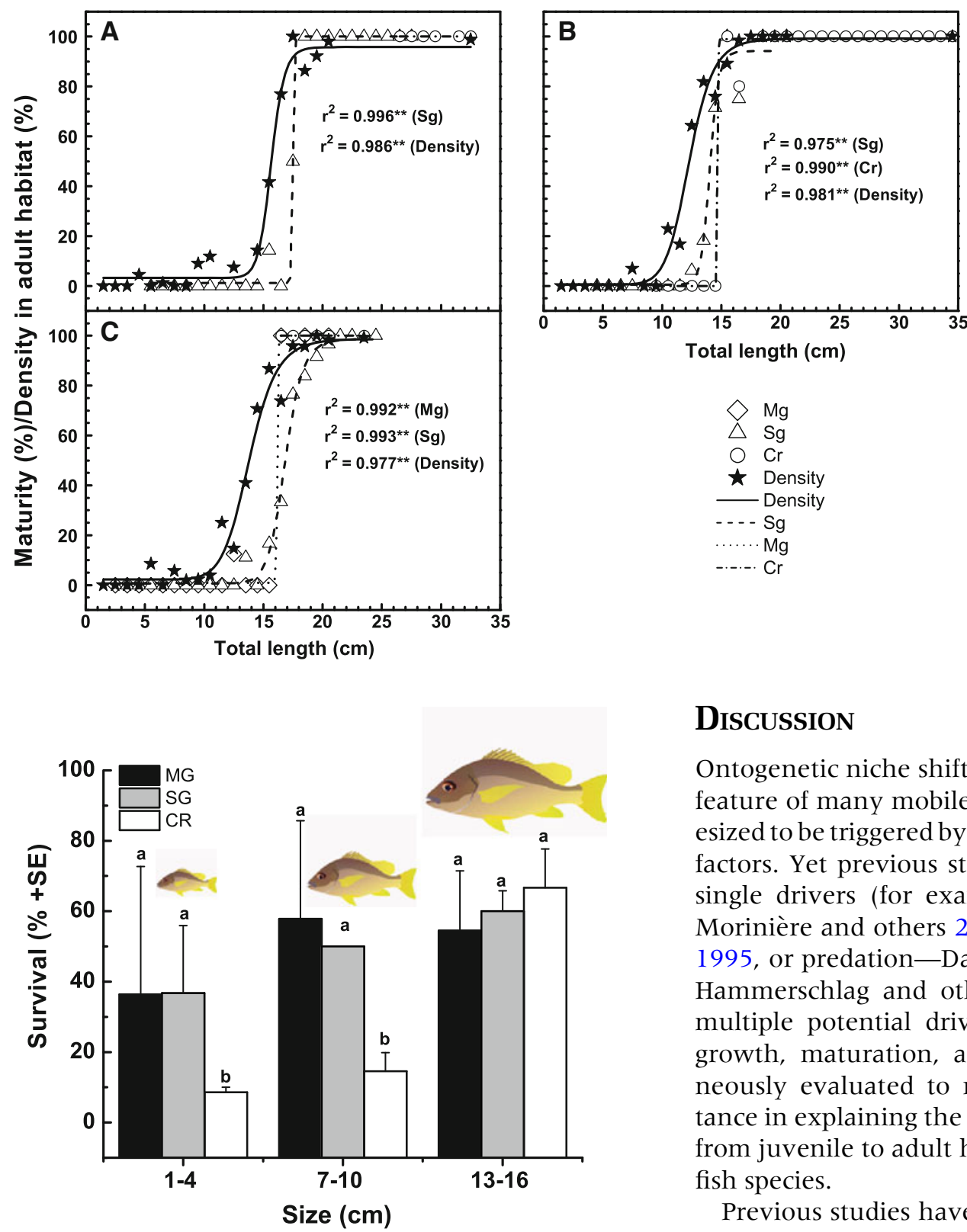

Figure 7. Survival rate (species combined) as a function of fish size from tethering experiments. Within each size class, significant differences among habitats $(P<0.05$, based on logistic regression) are indicated by letters ( $a$ and $b$ ) above the bars; if bars have a letter in common they do not differ, if bars do not have a letter in common they differ. $M g$ mangrove, $S g$ seagrass, $C r$ coral reef. Image credits: Tracey Saxby, IAN Image Library (ian.umces. edu/imagelibrary).

than $50 \%$ of all individuals in the size range $7-$ $10 \mathrm{~cm}$ in these habitats (Figure 7). For the largest size class $(13-16 \mathrm{~cm})$, survival rate was relatively high across habitats $(>60 \%)$ and no significant habitat-based differences were observed.

\section{Discussion} fish species. to the adult habitat.
Figure 6. Maturity (\% mature) and relative fish density in adult habitats (from visual census surveys; see "Materials and methods") as a function of fish size, fitted with sigmoid logistic curves for A Lethrinus harak, B Lethrinus lentjan, and $\mathbf{C}$ Lutjanus fulviflamma, with associated $r^{2}$ values. Open symbols and dotted lines represent maturity data, whereas black stars and solid lines indicate density data. ${ }^{*} P<0.001, M g$ mangrove, $S g$ seagrass, $\mathrm{Cr}$ coral reef, Density fish density in adult habitat.

Ontogenetic niche shifts are a pervasive life-history feature of many mobile organisms and are hypothesized to be triggered by a variety of biotic and abiotic factors. Yet previous studies have focused only on single drivers (for example, diet-Cocheret de la Morinière and others 2003b, maturation-Sheaves 1995, or predation-Dahlgren and Eggleston 2000; Hammerschlag and others 2010b). In this study, multiple potential drivers (diet, food abundance, growth, maturation, and survival) were simultaneously evaluated to reveal their relative importance in explaining the manifestation of niche shifts from juvenile to adult habitats for several coral reef

Previous studies have suggested that ontogenetic diet shifts in particular function as the tipping point for ontogenetic niche shifts in diverse ecosystems (Holbrook and Schmitt, 1992; Hyndes and others 1997; Moura and others 2008; Roznik and others 2009; Hultgren and Stachowicz 2010). However, neither diet shifts nor maturation triggered crosshabitat migrations in this study. Rather, ontogenetic diet shifts from small to large prey items occurred at relatively small sizes (approx. $\leq 5 \mathrm{~cm}$ body length), well prior to ontogenetic habitat shifts (occurring at $\sim 11-15 \mathrm{~cm}$; Figure 8 ), and fish matured at sizes larger than at which they moved

The ideal free distribution theory (Fretwell and Lucas 1970) predicts that foragers are distributed across habitat patches in proportion to their food 


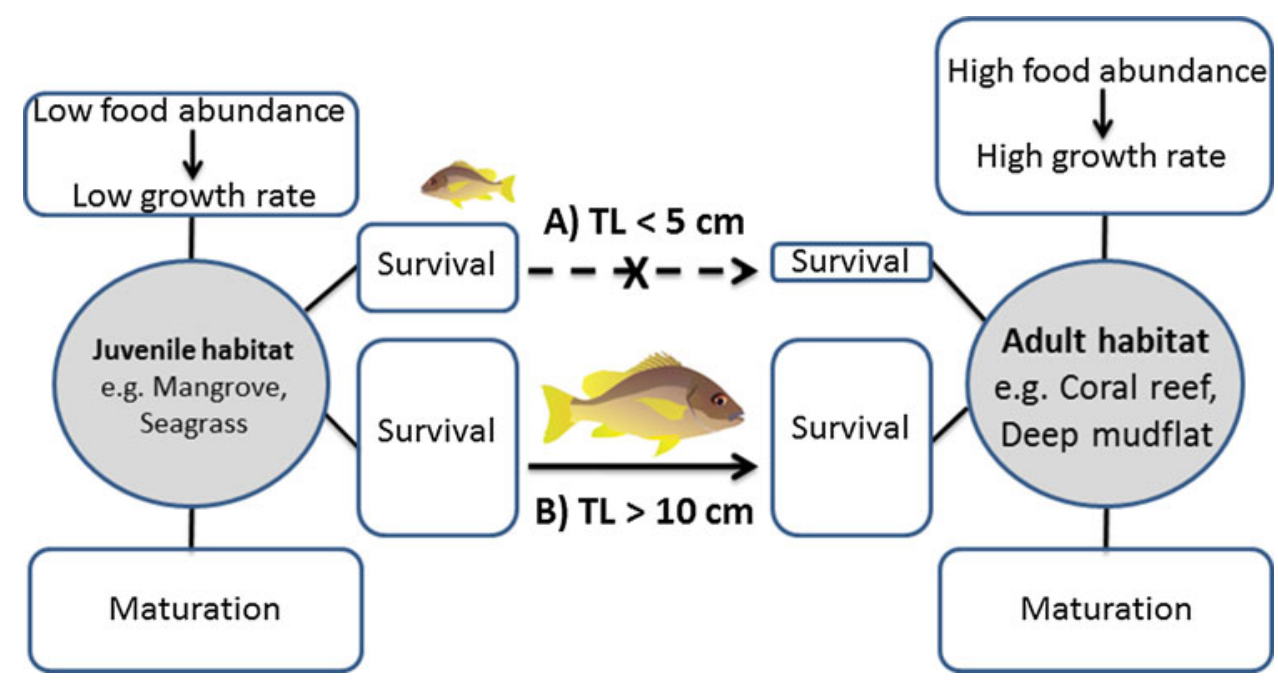

Figure 8. Conceptual model illustrating common ecological trade-offs for fish between juvenile nearshore and adult reef habitats. Ecological attributes for each habitat are listed in boxes. The large horizontal arrow indicates a unidirectional niche shift. Example 'A' notes a lack of movement (indicated by an $X$ ) from juvenile to adult habitats at fish sizes below $5 \mathrm{~cm}$ total length (TL) despite that at this size fish switch from feeding on smaller to larger prey items. At this size, survival is highest in juvenile habitats and fishes are restricted to these habitats despite several advantages that the adult habitat offers (high food abundance and fast growth). Example 'B' highlights large fish (>10 cm TL) that experience similar survival rates in juvenile versus adult habitats and elect to migrate to the more profitable adult reef habitat. Image credits: Tracey Saxby, IAN Image Library (ian.umces.edu/imagelibrary).

supply. In our study, both small and large food items were significantly more abundant, but juvenile fish densities lower in coral reef habitats compared to any other juvenile habitat type. Thus based on these data, it might be expected that larger juveniles would occupy and feed extensively in coral reef habitats where preferred prey items are considerably more abundant. However, this was not the case in this study and suggests that other factors were interacting with prey availability to create the ontogenetic niche shifts typically observed in coral reef ecosystems.

Similarly, there were more prey items available for L. harak and L. lentjan on coral reef habitats compared to seagrass bed habitats, indicating that the seagrass beds did not provide an optimal foraging habitat for either species. In contrast, for L. fulviflamma, the coral reef habitat did not contain more food items per individual fish compared to the seagrass bed habitat; however, this was not reflected in L. fulviflamma growth rates. Although for two fish species the mangroves provided equally high food availability per fish as on the reef, visual census surveys revealed that these species do not favor mangroves as juvenile habitat in this area (Kimirei and others 2011). Despite high productivity of certain consumer resources in mangrove habitats (Nagelkerken and others 2008), previous stable isotope studies have similarly indicated low dependency of fish on mangroves as a nutritional source (Layman 2007; Kruitwagen and others 2010; Heithaus and others 2011). Our comparison of prey availability, along with realized growth rate differences among habitats, provides further support that food availability was not the proximate driver for fish habitat utilization across the studied seascape (Figure 8).

High predation-risk habitats are generally avoided by individuals or size classes of fish that are predation-prone, regardless of the advantages these habitats offer in terms of food abundance (Werner and Hall 1988; Dahlgren and Eggleston 2000; Hammerschlag and others 2010a, b). For example, predation risk is typically higher on coral reefs than in back-reef or lagoon areas (Chittaro and others 2005; Dorenbosch and others 2009; Grol and others 2011) and in transition zones between refugia and feeding habitats (Hammerschlag and others $2010 b$ ). In this study, fish most likely traded off fast growth for safety by avoiding high predation-risk habitats (coral reef) and living in relatively slowgrowth environments (mangroves and seagrass beds). Previously, Grol and others (2011) showed that the decision by pelagic larval fish to settle into mangrove/seagrass habitat is driven by a much higher predation risk on the adult reef habitat, but this does not explain what triggers movement to the reef at larger body sizes at which fish have a 
similar predation risk across habitats. This study shows that although higher food abundances and growth potential drives ontogenetic niche shifts from 'safer' inshore juvenile habitats (mangroves and seagrass beds) to relatively 'risky' adult habitats (especially coral reefs), high predation risk delays movement into adult habitats until fish reach a size at which predation risk is similar across habits (see Figure 8).

The importance of Indo-Pacific coastal habitats (especially mangroves) as nurseries for coral reef fishes has been debated for decades (see reviews by Faunce and Layman 2009; Nagelkerken 2009). However, emerging evidence indicates that these habitats produce significant numbers of fish that move and recruit to adjacent coral reefs thereby enhancing reef fish populations (Nakamura and others 2008; Verweij and others 2008). Despite their ecological bottlenecks (low food abundance, low growth potential, low maturation rates), these habitats play a critical role as refugia for juveniles and as long-term sources of propagules to reefs for a variety of coral reef fish species. Furthermore, these fish populations provide an important source of protein and income for human populations in the tropics (Munro and William 1985; Munro 1996). The implications of the current study are that the production of juveniles by several habitats (Kimirei and others 2011; Nagelkerken and others 2012) and prevalent cross-ecosystem connectivity creates a 'portfolio effect' (Rypel and others 2012; Yates and others 2012) that can reduce variability in overall production of adults and enhance sustainability of coral reef fisheries. This 'bet-hedging' strategy may prove to increase in importance with the rapid degradation of coral reefs world-wide (for example, Jones and others 2004), with non-reef habitats buffering against local disturbances and associated loss of juvenile fish production on coral reefs. Incorporation of coastal ecosystem connectivity into the design of marine protected areas has already been shown to be beneficial for reef fish productivity (Edwards and others 2010; Nagelkerken and others 2012; Olds and others 2012), while it also supports populations of threatened reef fish species (Mumby and others 2004; Dorenbosch and others 2006).

This study serves as an important case study for how illumination of simple ecological trade-offs can yield a more complete understanding of complex ecosystems. For example, ontogenetic diet shifts and gonad maturation did not appear to be important drivers of ontogenetic niche shifts in this ecosystem type, even though these factors have been suggested as important in other environments
(Hansen and others 1989; Hyndes and others 1997). Rather, predation risk seemed to function as the primary filter inhibiting movements of individuals to more profitable adult habitats. However, although predation risk was clearly an important factor, high growth potential in adult habitats might also be critical under other circumstances as the extent to which predation-growth trade-offs might vary over different spatial and temporal scales remains unknown and unstudied. For example, could ontogenetic niche shifts occur earlier in life or at smaller sizes if predation risk is lessened through natural recruitment variability or over-fishing of predators by humans? Conversely, could niche shifts be delayed as a result of the ongoing reef degradation resulting in lower food availability and growth rates on coral reefs?

Threats to marine ecosystems are mounting such that marine protected areas are increasingly expected to fail to conserve current levels of diversity (Jones and others 2004). Many researchers have argued for improved integration of ecosystem-based theory into various management initiatives to abate these trends (Pikitch and others 2004; Lotze and others 2006). This study and several others have strongly suggested that simple ecological trade-offs (for example, the growth to predation risk trade-off) ultimately give rise to the ontogenetic habitat shifts observed in the life-cycles of myriad species (Dahlgren and Eggleston 2000; Grol and others 2011; Rypel and others 2012). We contend that a specific better understanding of ontogenetic niche shifts, and the ecological tradeoffs that promote them, would lead to improved conservation management of coral reef environments. For example, marine protected areas emphasize connectance of reefs to neighboring nearshore habitats such that ontogenetic fish migrations are allowed to occur (Mumby 2006; Nagelkerken and others 2012). Future studies might therefore explicitly evaluate the extent to which ecological trade-offs and ontogenetic niche shifts differ in managed versus natural ecosystems. Such studies would allow for consideration of novel management strategies aimed specifically at maximizing efficacy of marine protected areas and promoting coral reef fisheries sustainability.

\section{ACKNOWLEDGMENTS}

This study was funded through WOTRO Science for Global Development by the Netherlands Organisation for Scientific Research (NWO). I.N. was funded by a Vidi grant from NWO. M.T. was supported by Schure-Beijerinck-Popping Fonds, Graeve Francken 
Fund, and the AUV-Fund of the University of Amsterdam. P.B. was supported by the SchureBeijerinck-Popping Fonds, and D.H. was supported by the University of Groningen Marco Polo Fund. A.L.R. was supported by the USDA Forest Service, Southern Research Station, Center for Bottomland Hardwoods Research. We thank the administration and staff of the Mbegani Fisheries Development Centre (MFDC) for logistical support and research facilities. The staff of the Department of Aquatic Sciences and Fisheries of the University of Dar es Salaam are also thanked for their cooperation and for providing office space and research facilities. Appreciation is expressed to Niek Slooter, Estrella Tapias, Ben Griffioen, Coen Wagner, Peter Smittenaar, and Mathias Igulu for their invaluable field assistance, and Hassan and Mmanga for operating the research boat.

\section{OPEN ACCESS}

This article is distributed under the terms of the Creative Commons Attribution License which permits any use, distribution, and reproduction in any medium, provided the original author(s) and the source are credited.

\section{REFERENCES}

Adams AJ, Dahlgren CP, Kellison GT, Kendall MS, Layman CA, Ley JA, Nagelkerken I, Serafy JE. 2006. Nursery function of tropical back-reef systems. Mar Ecol Prog Ser 318:287-301.

Biebach H. 1983. Genetic determination of partial migration in the European Robin (Erithacus rubecula). Auk 100:601-6.

Brodersen J, Nilsson PA, Hansson LA, Skov C, Brönmark C. 2008. Condition-dependent individual decision-making determines cyprinid partial migration. Ecology 89:1195-200.

Carpenter KE. 1996. Morphometric pattern and feeding mode in emperor fishes (Lethrinidae, Perciformes). In: Marcus LF et al., Eds. Advances in morphometrics. New York: Plenum Press. p 479-87.

Chittaro PM, Usseglio P, Sale P. 2005. Variation in fish density, assemblage composition and relative rates of predation among mangrove, seagrass and coral reef habitats. Environ Biol Fishes 72:175-87.

Cocheret de la Morinière E, Pollux BJA, Nagelkerken I, Hemminga MA, Huiskes AHL, van der Velde G. 2003a. Ontogenetic dietary changes of coral reef fishes in the mangrove-seagrass-reef continuum: stable isotopes and gut-content analysis. Mar Ecol Prog Ser 246:279-89.

Cocheret de la Morinière E, Pollux BJA, Nagelkerken I, van der Velde G. 2003b. Diet shifts of Caribbean grunts (Haemulidae) and snappers (Lutjanidae) and the relation with nursery-tocoral reef migrations. Estuar Coast Shelf Sci 57:1079-89.

Cox GW. 1968. The role of competition in the evolution of migration. Evolution 22:180-92.

Dahlgren CP, Eggleston DB. 2000. Ecological processes underlying ontogenetic habitat shifts in a coral reef fish. Ecology $81: 2227-40$
Dorenbosch M, Grol MGG, Christianen MJA, Nagelkerken I, van der Velde G. 2005a. Indo-Pacific seagrass beds and mangroves contribute to fish density coral and diversity on adjacent reefs. Mar Ecol Prog Ser 302:63-76.

Dorenbosch M, Grol MGG, Nagelkerken I, van der Velde G. 2005b. Distribution of coral reef fishes along a coral reefseagrass gradient: edge effects and habitat segregation. Mar Ecol Prog Ser 299:277-88.

Dorenbosch M, Grol MGG, Nagelkerken I, van der Velde G. 2006. Seagrass beds and mangroves as potential nurseries for the threatened Indo-Pacific humphead wrasse, Cheilinus undulatus and Caribbean rainbow parrotfish, Scarus quacamaia. Biol Conserv 129:277-82.

Dorenbosch M, Grol MGG, de Groene A, van der Velde G, Nagelkerken I. 2009. Piscivore assemblages and predation pressure affect relative safety of some back-reef habitats for juvenile fish in a Caribbean bay. Mar Ecol Prog Ser 379:181-96.

Edgar GJ, Shaw C. 1995. The production and trophic ecology of shallow-water fish assemblages in southern Australia II. Diets of fishes and trophic relationships between fishes and benthos at Western Port, Victoria. J Exp Mar Biol Ecol 194:83-106.

Edwards HJ, Elliott IA, Pressey RL, Mumby PJ. 2010. Incorporating ontogenetic dispersal, ecological processes and conservation zoning into reserve design. Biol Conserv 143:457-70.

Faunce CH, Layman CA. 2009. Sources of variation that affect perceived nursery function of Mangroves. In: Nagelkerken I Ed. Ecological connectivity among tropical coastal ecosystems. Dordrecht: Springer. p 401-21.

Fretwell SD, Lucas HL. 1970. On territorial behaviour and other factors influencing habitat distribution in birds. I. Theoretical development. Acta Biotheor 19:16-36.

Fryxell JM, Sinclair ARE. 1988. Causes and consequences of migration by large herbivores. Trends Ecol Evol 3:237-41.

Galarowicz TL, Adams JA, Wahl DH. 2006. The influence of prey availability on ontogenetic diet shifts of a juvenile piscivore. Can J Fish Aquat Sci 63:1722-33.

Grol MGG, Nagelkerken I, Rypel AL, Layman CA. 2011. Simple ecological trade-offs give rise to emergent cross-ecosystem distributions of a coral reef fish. Oecologia 165:79-88.

Hammerschlag N, Heithaus MR, Serafy JE. 2010a. Influence of predation risk and food supply on nocturnal fish foraging distributions along a mangrove-seagrass ecotone. Mar Ecol Prog Ser 414:223-35.

Hammerschlag N, Morgan AB, Serafy JE. 2010b. Relative predation risk for fishes along a subtropical mangrove-seagrass ecotone. Mar Ecol Prog Ser 401:259-67.

Hansen LP, Jonsson B, Morgan RIG, Thorpe JE. 1989. Influence of Parr maturity on emigration of smolting Atlantic Salmon (Salmo salar). Can J Fish Aquat Sci 46:410-15.

Heithaus ER, Heithaus PA, Heithaus MR, Burkholder D, Layman CA. 2011 . Trophic dynamics in a relatively pristine subtropical fringing mangrove community. Mar Ecol Prog Ser 428:49-61.

Holbrook SJ, Schmitt RJ. 1992. Causes and consequences of dietery specialization in surfperch: patch choice and intraspecific competition. Ecology 73:402-12.

Hultgren KM, Stachowicz JJ. 2010. Size-related habitat shifts facilitated by positive preference induction in a marine kelp crab. Behav Ecol 21:329-36.

Hyndes GA, Platell ME, Potter IC. 1997. Relationships between diet and body size, mouth morphology, habitat and movements of six sillaginid species in coastal waters: implications for resource partitioning. Mar Biol 128:585-98. 
Hyslop EJ. 1980. Stomach content analysis: a review of methods and their application. J Fish Biol 17:411-29.

Jones GP, McCormick MI, Srinivasan M, Eagle JV. 2004. Coral decline threatens fish biodiversity in marine reserves. Proc Natl Acad Sci USA 101:8251-3.

Jonsson B, Jonsson N. 1993. Partial migration: niche shift versus sexual maturation in fishes. Rev Fish Biol Fisheries 3:348-65.

Kaitala A, Kaitala V, Lundberg P. 1993. A theory of partial migration. Am Nat 142:59-81.

Kaunda-Arara B, Ntiba JM. 1997. The reproductive biology of Lutjanus fulviflamma (Forsskål, 1775) (Pisces: Lutjanidae) in Kenyan inshore marine waters. Hydrobiologia 353:153-60.

Kimirei IA, Nagelkerken I, Griffioen B, Wagner C, Mgaya YD. 2011. Ontogenetic habitat use by mangrove/seagrass-associated coral reef fishes shows flexibility in time and space. Estuar Coast Shelf Sci 92:47-58.

Kruitwagen G, Nagelkerken I, Lugendo BR, Mgaya YD, Bonga SEW. 2010. Importance of different carbon sources for macroinvertebrates and fishes of an interlinked mangrove-mudflat ecosystem (Tanzania). Estuar Coast Shelf Sci 88:464-72.

Kulmiye AJ, Ntiba JM, Kisia SM. 2002. Some aspects of the reproductive biology of the thumbprint emperor, Lethrinus harak (ForsskOEl, 1775), in Kenyan coastal waters. Westen Indian Ocean Journal of Marine Science 1:135-44.

Laegdsgaard P, Johnson C. 2001. Why do juvenile fish utilise mangrove habitats? J Exp Mar Biol Ecol 257:229-53.

Layman CA. 2007. What can stable isotope ratios reveal about mangroves as fish habitat? Bull Mar Sci 80:513-27.

Leggett WC. 1977. The ecology of fish migrations. Annu Rev Ecol Syst 8:285-308.

Lotze HK, Lenihan HS, Bourque BJ, Bradbury RH, Cooke RG, Kay MC, Kidwell SM, Kirby MX, Peterson CH, Jackson JBC. 2006. Depletion, degradation, and recovery potential of estuaries and coastal seas. Science 312:1806-9.

Lundberg P. 1987. Partial bird migration and evolutionary stable strategies. J Theor Biol 125:351-60.

Lundberg P. 1988. The evolution of partial migration in birds. Trends Ecol Evol 3:172-5.

Maceina MJ. 1988. A simple grinding procedure for sectioning otoliths. North Am J Fish Manag 8:141-3.

McCormick MI. 1998. Condition and growth of reef fish at settlement: is it important? Aust J Ecol 23:258-64.

McCormick MI, Makey LJ. 1997. Post-settlement transition in coral reef fishes: overlooked complexity in niche shifts. Mar Ecol Prog Ser 153:247-57.

Moura T, Figueiredo I, Farias I, Serra-Pereira B, Neves A, Borges MDF, Gordo LS. 2008. Ontogenetic dietary shift and feeding strategy of Raja undulata Lacepede, 1802 (Chondrichthyes: Rajidae) on the Portuguese continental shelf. Sci Mar 72:31118.

Mumby PJ. 2006. Connectivity of reef fish between mangroves and coral reefs: algorithms for the design of marine reserves at seascape scales. Biol Conserv 128:215-22.

Mumby PJ, Edwards AJ, Arias-Gonzalez JE, Lindeman KC, Blackwell PG, Gall A, Gorczynska MI, Harborne AR, Pescod CL, Renken H, Wabnitz CCC, Llewellyn G. 2004. Mangroves enhance the biomass of coral reef fish communities in the Caribbean. Nature 427:533-6.

Munro JL. 1996. Scope and management of tropical reef fisheries. In: Polunin NVC, Roberts CM, Eds. Reef fisheries. London: Chapman and Hall. p 1-14.
Munro JL, William DM. 1985. Assessment and management of coral reef fisheries: biological, environmental and socio-economic aspects. In: Proceedings of the 5th International Coral Reef Congress, Tahiti. pp 545-81.

Nagelkerken I. 2007. Are non-estuarine mangroves connected to coral reefs through fish migration? Bull Mar Sci 80:595-607.

Nagelkerken I. 2009. Evaluation of nursery function of mangroves and seagrass beds for tropical decapods and reef fishes: patterns and underlying mechanisms. In: Nagelkerken I, Ed. Ecological connectivity among tropical coastal ecosystems. Dordrecht: Springer. p 357-400.

Nagelkerken I, Roberts CM, van der Velde G, Dorenbosch M, van Riel MC, Cocheret de la Moriniere E, Nienhuis PH. 2002. How important are mangroves and seagrass beds for coral-reef fish? The nursery hypothesis tested on an island scale. Mar Ecol Prog Ser 244:299-305.

Nagelkerken I, Blaber SJM, Bouillon S, Green P, Haywood M, Kirton LG, Meynecke J-O, Pawlik J, Penrose HM, Sasekumar A, Somerfield PJ. 2008. The habitat function of mangroves for terrestrial and marine fauna: a review. Aquat Bot 89:155-85.

Nagelkerken I, Grol MGG, Mumby PJ. 2012. Effects of marine reserves versus nursery habitat availability on structure of reef fish communities. PLoS ONE 7:e36906.

Nakamura Y, Horinouchi M, Shibuno T, Tanaka Y, Miyajima T, Koike I, Kurokura H, Sano M. 2008. Evidence of ontogenetic migration from mangroves to coral reefs by black-tail snapper Lutjanus fulvus: stable isotope approach. Mar Ecol Prog Ser 355:257-66.

Ntiba MJ, Jaccarini V. 1990. Gonad maturation and spawning times of Siganus sutor off the Kenya coast: evidence for definite spawning seasons in tropical fish. J Fish Biol 37:315-25.

Olds AD, Connolly RM, Pitt KA, Maxwell PS. 2012. Habitat connectivity improves reserve performance. Conserv Lett 5:56-63.

Pikitch EK, Santora C, Babcock EA, Bakun A, Bonfil R, Conover DO, Dayton P, Doukakis P, Fluharty D, Heneman B, Houde ED, Link J, Livingston PA, Mangel M, McAllister MK, Pope J, Sainsbury KJ. 2004. Ecosystem-based fishery management. Science 305:346-7.

Post DM. 2003. Individual variation in the timing of ontogenetic niche shifts in largemouth bass. Ecology 84:1298-310.

Roznik EA, Johnson SA, Greenberg CH, Tanner GW. 2009. Terrestrial movements and habitat use of gopher frogs in longleaf pine forests: a comparative study of juveniles and adults. For Ecol Manage 259:187-94.

Rypel AL. 2011. River impoundment and sunfish growth. River Res Appl 27:580-90.

Rypel AL, Pounds KM, Findlay RH. 2012. Spatial and temporal trade-offs by Bluegills in floodplain river ecosystems. Ecosystems 15:555-63.

Schindler DE. 1999. Migration strategies of young fishes under temporal constraints: the effect of size-dependent overwinter mortality. Can J Fish Aquat Sci 56(Suppl. 1):61-70.

Sheaves M. 1995. Large lutjanid and serranid fishes in tropical estuaries: are they adults or juveniles? Mar Ecol Prog Ser 129:31-40.

Shibuno T, Nakamura Y, Horinouchi M, Sano M. 2008. Habitat use patterns of fishes across the mangrove-seagrass-coral reef seascape at Ishigaki Island, southern Japan. Ichthyol Res 55:218-37.

Skov C, Baktoft H, Brodersen J, Bronmark C, Chapman B, Hansson LA, Nilsson PA. 2011. Sizing up your enemy: indi- 
vidual predation vulnerability predicts migratory probability. Proc R Soc Ser B 278:1414-18.

Travers MJ, Newman SJ, Potter IC. 2006. Influence of latitude, water depth, day vs. night and wet vs. dry periods on the species composition of reef fish communities in tropical Western Australia. J Fish Biol 69:987-1017.

Ueda H. 2011. Physiological mechanism of homing migration in Pacific salmon from behavioral to molecular biological approaches. Gen Comp Endocrinol 170:222-32.

Verweij MC, Nagelkerken I, Wartenbergh SLJ, Pen IR, van der Velde G. 2006. Caribbean mangroves and seagrass beds as daytime feeding habitats for juvenile French grunts, Haemulon flavolineatum. Mar Biol 149:1291-9.
Verweij MC, Nagelkerken I, Hans I, Ruseler SM, Mason PRD. 2008. Seagrass nurseries contribute to coral reef fish populations. Limnol Oceanogr 53:1540-7.

Werner EE, Gilliam JF. 1984. The ontogenetic niche and species interactions in size-structured populations. Annu Rev Ecol Syst 15:393-425.

Werner EE, Hall DJ. 1988. Ontogenetic habitat shifts in bluegill: the foraging rate-predations risk trade-off. Ecology 69:135266.

Yates PM, Heupel MR, Tobin AJ, Simpfendorfer CA. 2012. Diversity in young shark habitats provides the potential for portifolio effects. Mar Ecol Prog Ser 458:269-81. 